\title{
AIDS em Mulheres Adultas no Município do Rio de Janeiro
}

\footnotetext{
* Depto. Epidemiologia e Meto dos Quantitativas em SaAde PAblica, Ensp/Fiocruz.

* Coordenadoria de Epidemiologia, Secretaria Municipal de Salde, Prefeitura do Rio de Janeiro.
}

\author{
Rosalina Jorge Koifman *** \\ Eleonora Pati Quinhöes ** \\ Gina Torres Rego Monteiro *** \\ Regina Rodrigues ** \\ Sergio Koifman ***
}

Este trabalho apresenta as principais caracteristicas epidemiologicas descritivas da distribuiçāo de AIDS em mulheres adultas no Munictpio do Rio de Janeiro, ao longo da década de oitenta. Pode-se observar uma participação crescente das mesmas, com elevadas taxas de incidência comparativamente com coeficientes para todo o Brasil, bem como para o Canadá. A contaminaçāo transfusional, predominante no intcio da epidemia, vem cedendo lugar à transmissão sexual e por utilizaçâo de drogas endovenosas. Observa-se, também, uma distribuição espacial definida na ocorrência dos casos, com participação crescente das mulheres jovens. $O$ trabalho ressalta a importância da tuberculose como segunda causa de complicação mais freqüente entre as infecçōes oportunistas observadas. Finalmente, sâo apontadas algumas das questōes cruciais a serem abordadas no futuro, tendo em vista a compreensão e o controle na difusão da epidemia no grupo estudado.

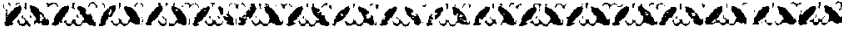

\section{INTRODUÇÃO}

Uma das principais características da epidemia de AIDS consiste no fato de que não têm sido observadas modificações importantes de seus grupos de risco, decorrida uma década desde a identificação dos primeiros casos da doença e, posteriormente, de seu agente viral no início dos anos oitenta (CDC,1987; Morgan,1986; Chin, 1989). Até o presente momento, o sangue $\mathrm{e} o$ sêmen são as únicas vias conhecidas de transmissão da doença na população (Man, 88).

A partir desta constatação, os serviços de Saúde Pública de vários países têm adotado medidas específicas de prevenção, com o objetivo de controlar a expansão da epidemia. Entre estas medidas estão aquelas dirigidas, especialmente, aos grupos de maior risco (homossexuais masculinos, usuários de drogas injetá- 
veis, receptores de sangue e derivados etc), bem como aquelas relativas ao conjunto da população (controle da qualidade dos bancos de sangue, medidas voltadas para a prática de sexo seguro etc).

A variaçāo observada na distribuição da doença a nível internacional, e mesmo nacional, é devida, aparentemente, à heterogeneidade na predominância dos diferentes grupos de risco em cada local. Assim, por exemplo, as cidades de Santos e São José do Rio Preto, ambas no estado de São Paulo, apresentam elevados coeficientes de incidência de AIDS na população, provavelmente, em conseqũência da difusão do consumo de drogas injetáveis - embora em grupos populacionais distintos (adultos na primeira e adolescentes na segunda cidade), fatos estes talvez decorrentes da dinâmica distinta do consumo de drogas injetáveis em ambas regiōes.

Entretanto, existem, ainda, lacunas no conhecimento da doença, como, por exemplo, em relação ao papel da transmissão heterossexual (Goeddert, 1987), da infecção perinatal (Blanche, 1987; Hoff et al., 1988; Mok, 1987; Nzilambi, 1987; Seprini, 1987), das infecçôes oportunistas; em uma população com desnutriçăo prevalente etc).

Entre os tópicos da epidemiologia da AIDS merecendo aprofundamento inclui-se, também, o papel jogado pelas mulheres na expansã̉o do processo epidémico (Johnston e Webster, 1989), uma vez que, apesar da elevada transmissão sexual homem-mulher, a via inversa näo tem apresentado as mesmas características de eficácia. Este fato talvez seja uma das razóes para a relativa debilidade da transmissão heterossexual, após pelo menos dez anos de difusão conhecida desta pandemia.

Entre os marcadores identificados como fatores progn6sticos da transmissão sexual homem-mulher, encontram-se: o número de parceiros sexuais (Fisch, 1988a), bern como, entre mulheres com parceiros infectados, a presença de antecedentes de doenças sexualmente transmissíveis, durante os últimos cinco anos; a existência de um quadro clínico de AIDS no parceiro, bem como a prática de sexo anal (European Study Group, 1989). Existem, também, evidências de que a presença de lesões genitais por sífilis, herpes simples e outros agentes esteja associada à elevaçäo dos riscos de infeç̧ão pelo HIV em mulheres (Fisch, 1988b).

Entretanto, este quadro vem sofrendo um processo de transformação (Starcher et al., 1988), existindo países africanos onde a transmissão heterossexual já ocupa um lugar de destaque na difusão da epidemia. Neste sentido, existem inclusive questionamentos sobre a possibilidade de já encontrarmo-nos no país a caminho de um processo de transição para o pađrão africano Cadernos de Saúde Páblica, RJ, 7 (2): 232-250, abr/jun, 1991 
de difusāo da epidemia. Por outro lado, é igualmente oportuno observar que alguns estudos com prostitutas têm demonstrado altos níveis de infecção pelo HIV, entre mulheres usuárias de drogas injetáveis, e que estes nfveis de soropositividade foram quase quatro vezes maiores que aqueles observados em prostitutas não-usuárias de drogas injetáveis (CDC, 1986), o que revela a importância na abordagem dos distintos mecanismos, envolvendo o fenômeno da infecção nas mulheres.

Este trabalho pretende apresentar, de forma preliminar, algumas características epidemiológicas da AIDS em mulheres adultas no Município do Rio de Janeiro (MRJ), procurando tecer consideraçōes sobre sua distribuição comparativamente, sempre que possível, com aquelas verificadas em outras localidades.

\section{MATERIAL E MÉTODOS}

O presente estudo foi realizado, a partir das informaçōes contidas no sistema de vigilância epidemiológica da AIDS, realizado pela Secretaria Municipal de Saúde do Rio de Janeiro (SMSRJ). Este sistema realiza, rotineiramente, a investigação hospitalar de todos os casos notificados de AIDS, desde sua implantação em 1984, tendo descentralizado, posteriormente, suas atividades em 1986. Para tanto, utiliza uma ficha de coleta de dados estruturada de acordo com a ficha nacional de notificação, bem como a ficha de vigilância epidemiológica comum aos sistemas estadual e municipal de investigação da doença.

A tế 30 de maio de 1990 haviam sido notificados 3807 casos suspeitos de AIDS à SMSRJ, dos quais 429 relativos a mulheres maiores de 14 anos. Nesta ocasião, 216 casos em mulheres adultas haviam sido investigados, sendo confirmados 180 casos de acordo com os critérios definidos pelo CDC, posteriormente modificados, e adotados intemacionalmente (CDC, 1985). Esta cifra encontra-se largamente subestimada, uma vez que a paralisação de atividades durante as greves no setor saúde em 1988, 1989 e 1990 acarretou o acúmulo de grande número de casos notificados e ainda não investigados.

Este estudo apresenta algumas das principais características epidemiológicas da distribuição conhecida da doença em mulheres adultas no MRJ, sendo as mesmas comparadas, sempre que possível, com as características observadas em todo o Brasil e no Canadá. Para o cálculo das taxas de incidência - ainda que subestimadas no caso do MRJ pelos motivos acima apresentados -, foram utilizadas as populações estimadas para períodos específicos obtidas através de projeçōes com dados censitários (Fibge, 1980; WHO, 1980-89). Além dos coeficientes de incidência, é apre- 
sentada a distribuição dos casos em mulheres adultas no MRJ, segundo atividade ocupacional, categoria de transmissão, faixa etária ao diagnóstico, estado civil e principais complicações observadas na evolução do quadro clínico da doença. A distribuição espacial dos casos foi realizada, considerando-se tanto a regiāo administrativa de residência, como as áreas programáticas a elas relacionadas (AP1 - região central; AP2 - zona sul e zona norte; AP3 - subúrbios; AP4 Barra e jacarepaguá; AP5 - zona oeste), objetivando, assim, traçar um perfil deste tipo de distribuição em termos de uma relativa homogeneidade geográfica $\mathrm{e}$ sócio-econômica no MRJ.

\section{RESULTADOS}

Através do gráfico I pode-se observar a distribuição da epidemia em mulheres no Rio de Janeiro, no Brasil e no Canadá, ao longo da década de oitenta. A observação das três curvas revela a importância do problema no Município do Rio de Janeiro, mesmo considerando-se que as taxas ora apresentadas encontram-se aquém da realidade devido a não-atualização do total de casos investigados nesta região.

A magnitude do problema pode ser analisada de outra perspectiva, através da razão de casos em homens e mulheres nas três localidades, conforme apresentado na Tabela I. Enquanto no Canadá a proporção de casos em mulheres encontra-se relativamente estabilizada, desde 1984, ela vem declinando rapidamente ao longo da década em nosso país e, particularmente, no Rio de Janeiro, onde em 1989 ela já alcançava a cifra de um caso em mulher adulta para cada cinco casos em homens também adultos.

A distribuição dos casos, segundo categoria de exposição (tabela $\amalg$ ), revela, também, diferenças importantes nas três áreas. Enquanto mais da metade dos casos em mulheres adultas canadenses foram atribuídos à exposição sexual, observou-se, no Brasil, uma grande influência das drogas endovenosas na contaminação das mesmas $(38 \%)$; já no $\mathrm{MRJ}$, o peso da contaminação transfusional foi predominante, sendo da ordem de $45 \%$, até 1989 .

Uma visão mais dinâmica deste processo é visualizada com a distribuição temporal destas categorias de exposição (tabela III). Pode-se visualizar que, embora o maior peso da contaminação de mulheres cariocas maiores de 14 anos seja, ainda, através da via transfusional - no período de 1986-87, ela chegou a ser responsável por $65 \%$ dos casos! - é crescente a magnitude adquirida pelas drogas injetáveis a partir do estabelecimento de políticas setoriais, visando à melhoria no controle de qualidade dos bancos de sangue.

Cadernos de Saúde Pública, RJ, 7 (2): 232-250, abr/jun, 1991 


\section{GRÅFICO I}

\section{Incidência de AIDS em Mulheres Adultas, Município do Rio de Janeiro, Brasil e Canadá, 1984 - 1989}
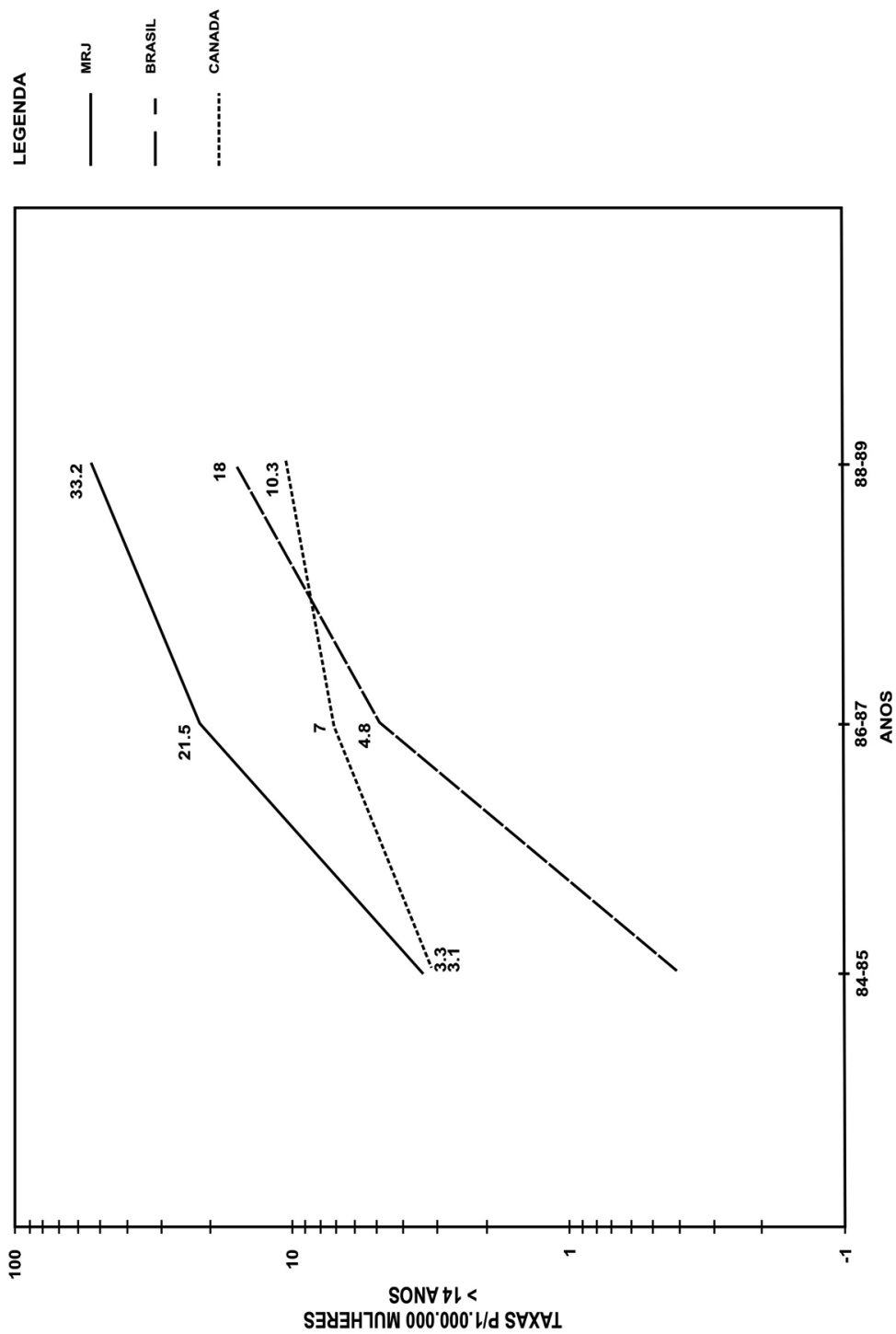


\section{TABELA I}

Casos de A'IDS em Maiores de 14 Anos,

Segundo Sexo Por Ano de Diagnóstico,

Município do Rio de Janeiro, Brasil e Canadá, $1982-89$

\begin{tabular}{|c|c|c|c|}
\hline Local & $\begin{array}{c}\text { Homens } \\
\mathrm{N}:\end{array}$ & $\begin{array}{c}\text { Mulheres } \\
\mathrm{N}:\end{array}$ & Razäo M/F \\
\hline
\end{tabular}

Rio de Janeiro

$\begin{array}{rrrr}1984 & 19 & 2 & 10 / 1 \\ 1985 & 73 & 5 & 15 / 1 \\ 1986 & 97 & 17 & 6 / 1 \\ 1987 & 334 & 31 & 11 / 1 \\ 1988 & 381 & 75 & 5 / 1 \\ 1989 & 223 & 50 & 5 / 1\end{array}$

Brasil

$\begin{array}{rrrc}1980-1984 & 147 & 2 & 73 / 1 \\ 1985 & 447 & 13 & 34 / 1 \\ 1986 & 865 & 44 & 20 / 1 \\ 1987 & 1856 & 171 & 11 / 1 \\ 1988 & 2904 & 344 & 8 / 1 \\ 1989 & 4267 & 414 & 10 / 1\end{array}$

Canadá

$\begin{array}{lrrr}1984 & 142 & 8 & 18 / 1 \\ 1985 & 314 & 22 & 14 / 1 \\ 1986 & 530 & 26 & 20 / 1 \\ 1987 & 797 & 44 & 18 / 1 \\ 1988 & 891 & 49 & 18 / 1 \\ 1989 & 893 & 56 & 16 / 1\end{array}$


ANÁLISE

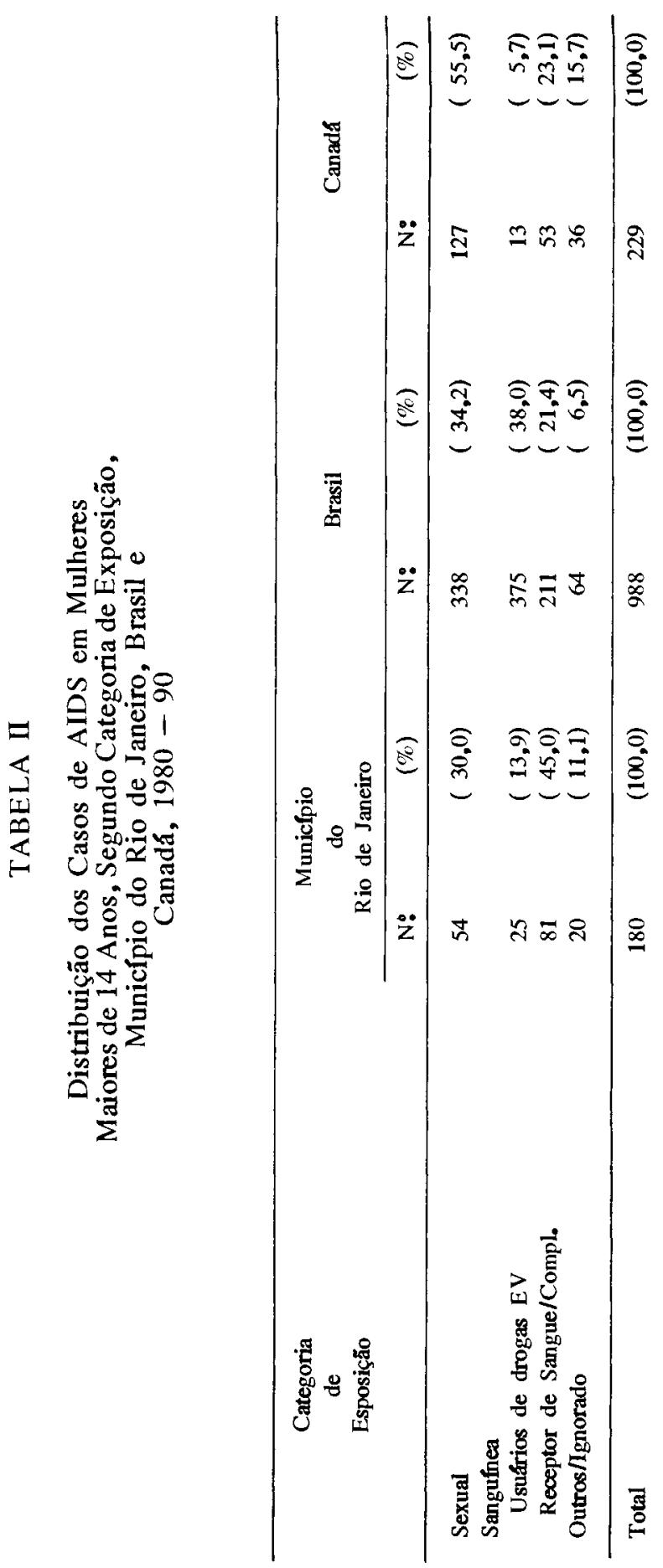



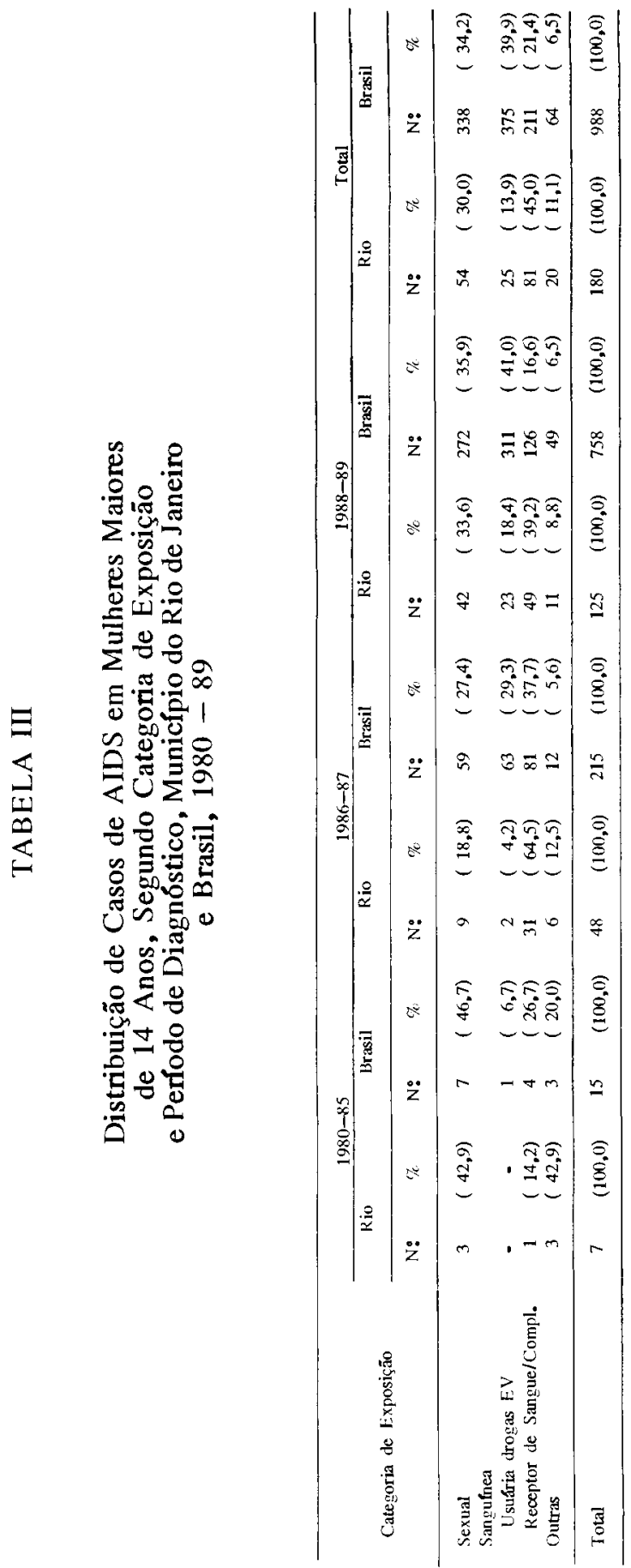
Em relação à distribuição etária de casos de AIDS em mulheres adultas, o comportamento observado no MRJ, no Brasil e no Canadá (tabela IV), é relativamente similar em seu conjunto - exceto pela maior freqüência de casos em mulheres canadenses maiores de cinqüenta anos -, com medianas de idade ao diagnóstico, respectivamente, da ordem de $34,2,31,0$ e 34,8 anos. Contudo, uma análise mais detalhada desta variável com o tipo de contaminação observada no MRJ (tabela V) revela que a maior proporção de casos com transmissão sexual reside na faixa etária de 30-39 anos (aproximadamente 43\%), enquanto que na categoria de usuárias de drogas injetáveis, o grupo mais atingido foi o de adultas jovens, de $20-29$ anos $(60 \%)$. Já o estrato de mulheres com contaminação transfusional revelou uma relativa tendência a homogeneização das proporçöes nas diferentes faixas etárias, principalmente de 20 a 59 anos, quando tende a ser maior a frequeência de oportunidades, favorecendo tal tipo de contaminaçāo.

A distribuição de casos, segundo estado civil e categoria de transmissão, revela que as maiores proporçōes de mulheres, tanto com transmissão sexual, como através da utilização de drogas injetáveis eram solteiras (48 e $72 \%$ respectivamente), ao contrário daquelas com transmissão via recepçã̄o de sangue e complemento nas quais observou-se a predominância de mulheres casadas (tabela VI).

\section{TABELA IV}

Distribuição de Casos de AIDS em Mulheres Maiores de 14 Anos, Munićpio do Rio de Janeiro, Brasil e Canadá, $1980-90$

\begin{tabular}{|c|c|c|c|c|c|c|}
\hline \multirow{2}{*}{$\begin{array}{l}\text { Faixa } \\
\text { Etária } \\
\text { (Anos) }\end{array}$} & \multicolumn{2}{|c|}{$\begin{array}{c}\begin{array}{c}\text { Municlpio * } \\
\text { do }\end{array} \\
\text { Rio de Janeiro }\end{array}$} & \multicolumn{2}{|c|}{ Brasil } & \multicolumn{2}{|c|}{ Canadá } \\
\hline & $\mathrm{N}:$ & $\%$ & N: & $\%$ & $\mathrm{~N}:$ & $\%$ \\
\hline $15-19$ & 7 & $(3,9)$ & 45 & $(4,6)$ & 3 & $(1,3)$ \\
\hline $20-29$ & 55 & $(30,6)$ & 400 & $(40,5)$ & 74 & $(32,3)$ \\
\hline $30-39$ & 59 & $(32,8)$ & 317 & $(32,1)$ & 72 & $(31,4)$ \\
\hline $40-49$ & 28 & $(15,6)$ & 129 & $(13,1)$ & 27 & $(11,8)$ \\
\hline 50 ou mais & 26 & $(14,4)$ & 90 & $(9,1)$ & 53 & $(23,1)$ \\
\hline Ignorado & 5 & $(2,8)$ & 7 & $(0,7)$ & - & - \\
\hline Total & 180 & $(100,0)$ & 988 & $(100,0)$ & 229 & $(100,0)$ \\
\hline
\end{tabular}

* $1982-89$ 


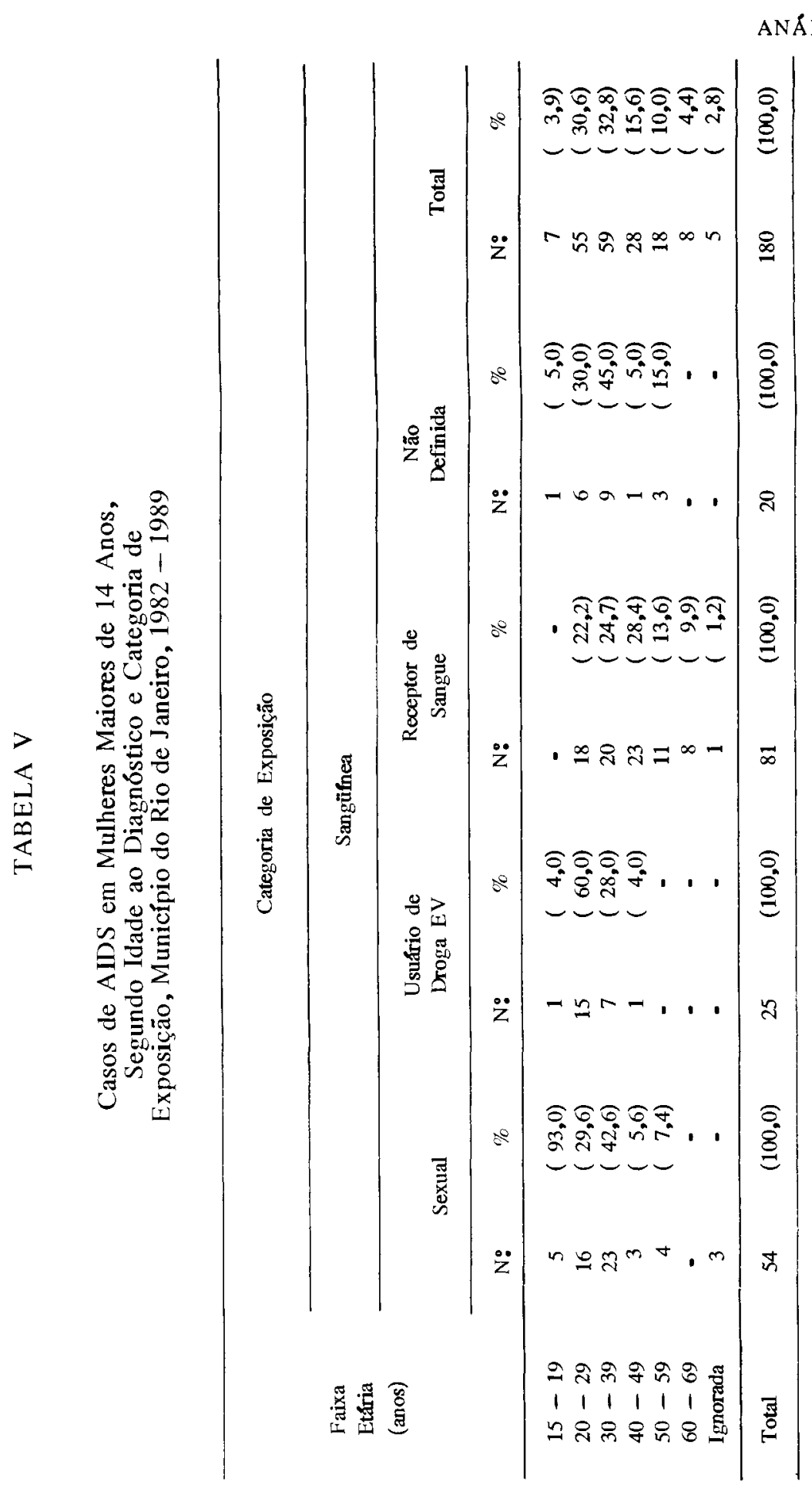




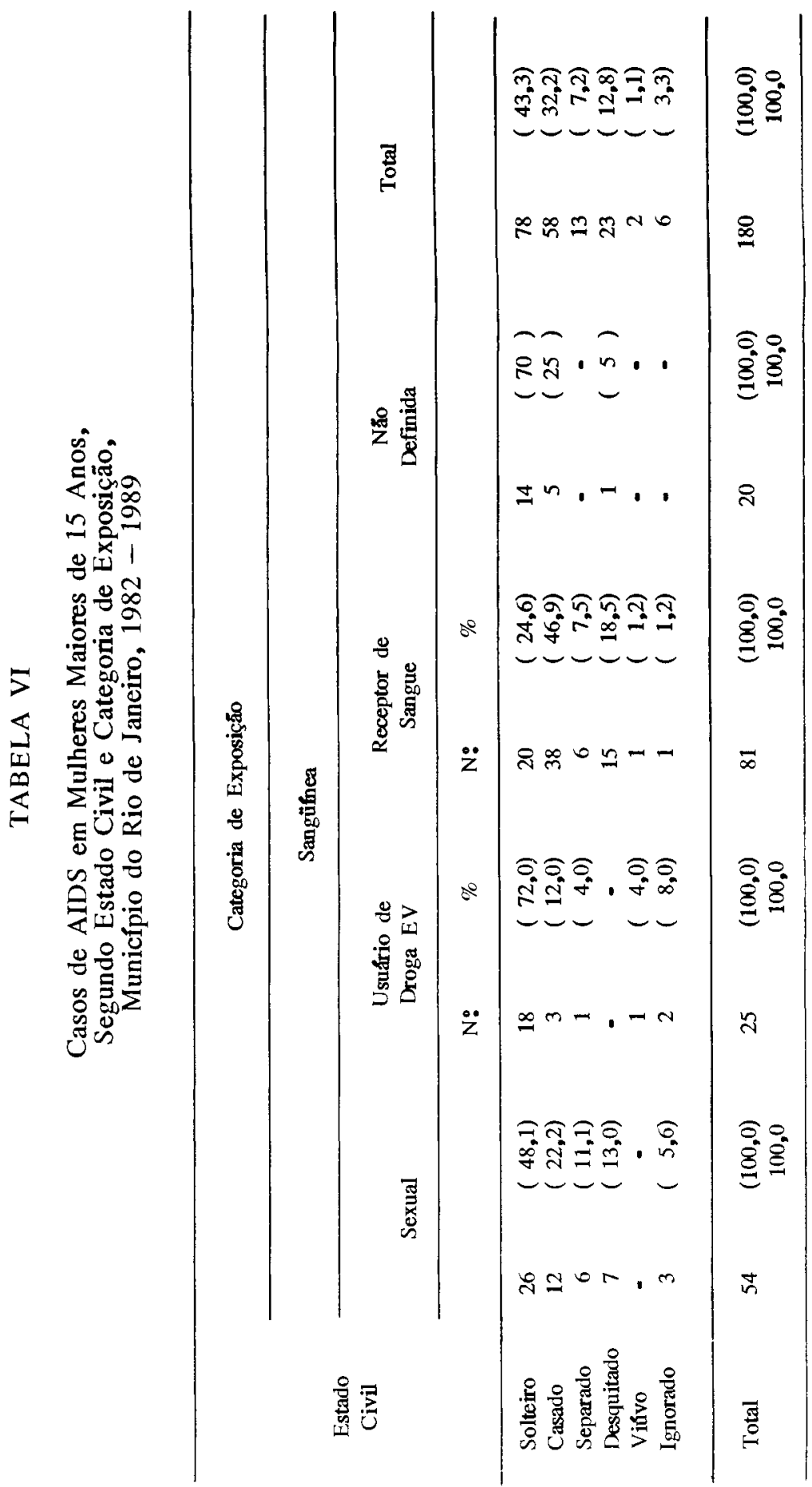


Em relação à atividade ocupacional (tabela VII), um terço dos casos ocorreu em donas-de-casa, seguindo-se em ordem decrescente as trabalhadoras domésticas $(14 \%)$ e prostitutas $(12 \%)$. E, também, interessante observar os distintos pesos assumidos por cada categoria de transmissão nos diferentes grupos ocupacionais (tabela VIII); assim, embora alguns estratos contem com escasso número de observaçōes, aproximadamente a metade das donas-de-casa, bem como mais de $60 \%$ das profissionais de nivel superior, tiveram contaminação de origem transfusional, perfil este relativamente distinto daquele observado entre as trabalhadoras domésticas e as prostitutas.

Do ponto de vista da distribuição espacial dos casos de AIDS em mulheres adultas no MRJ, as tabelas IX e $X$ revelam a marcada heterogeneidade entre as distintas regiōes, tanto do ponto de vista da distribuição isolada dos coeficientes, como do padrão, segundo categoria de transmissão. Em primeiro lugar, $\varepsilon$ oportuno ressaltar a magnitude das taxas de incidência verificadas na AP1, independentemente da categoria de transmissão analisada, sendo todas elas superiores àquelas observadas nas demais áreas programáticas do MRJ.

\section{TABELA VII}

Distribuição dos Casos de AIDS em Mulheres Maiores de 14 Anos, Segundo Ocupação, Município do Rio de Janeiro, $1982-89$

\begin{tabular}{lrr}
\hline Ocupação & N: & $\%$ \\
\hline Donas-de-casa & 61 & 33,9 \\
Trabalhadoras domEsticas & 26 & 14,4 \\
Prostitutas & 12 & 6,7 \\
Auxiliares de Escritório & 9 & 5,0 \\
Serviços de Estética & 7 & 3,9 \\
Profissionais de Saúde & 6 & 3,3 \\
Outras Profissionais & & \\
de Nfvel Superior & 5 & 2,8 \\
Costureiras & 5 & 2,8 \\
Professoras & 4 & 2,2 \\
Trabalhadoras Indústria & 4 & 2,2 \\
Artistas & 3 & 1,7 \\
Estudantes & 3 & 1,7 \\
Outras & 35 & 19,4 \\
\hline Total & 180 & 100,0 \\
\hline
\end{tabular}




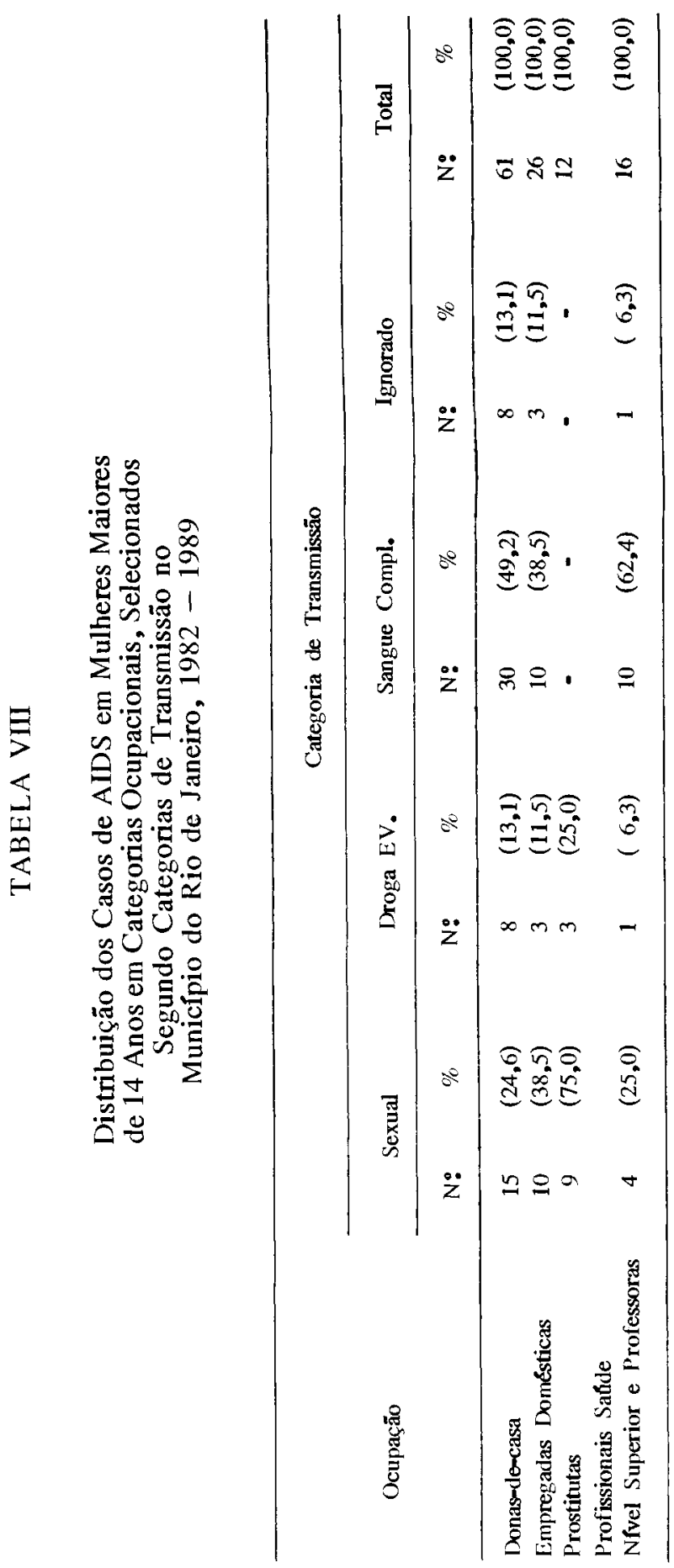




\section{TABELA IX}

Coeficientes de Incidência de AIDS

Em Mulheres Maiores de 14 Anos no

Município dó Rio de Janeiro - $1982-89$

\begin{tabular}{lc}
\hline Regiăo Administrativa & Coeficiente \\
\hline Portuária & 447,7 \\
Praça da Bandeira & 203,9 \\
Centro & 139,9 \\
Madureira & 133,2 \\
Vila Isabel & 128,7 \\
Engenho de Dentro & 121,0 \\
Gávea & 107,6 \\
Flamengo & 91,6 \\
Tijuca & 81,9 \\
Săo Cristóvăo & 81,8 \\
Copacabana & 74,7 \\
Penha & 70,1 \\
Ramos & 69,0 \\
Jacarepaguá & 52,5 \\
Santa Tereza & 51,1 \\
Engenho da Rainha & 50,8 \\
Anchieta & 43,4 \\
Bangu & 40,2 \\
Campo Grande & 33,3 \\
Ilha do Governador & 32,0 \\
Santa Cruz & 14,1 \\
& \\
Munictpio do Rio de Janeiro & 78,1 \\
\hline
\end{tabular}

* Taxa por 1.000 .000 de mulheres maiores de 14 anos.

Por outro lado, esta região caracteriza-se pela importância da transmissão sexual, com coeficientes até três vezes superiores aos das outras áreas. $\mathrm{Na}$ maioria das demais áreas programáticas, o maior peso da transmissão é devido à contaminação transfusional. Em relação à transmissão, através do consumo de drogas injetáveis, observa-se a concentração maciça de casos na área central (AP1) e zonas sul e norte (AP2).

Finalmente, a análise das infecçōes oportunistas, ocorridas durante a evolução clínica destas mulheres (tabela XI), apresenta como dado relevante o papel da tuberculose no universo estudado, ocupando o segundo lugar entre as infecçōes mais reportadas $(29 \%$, o que representa o dobro da proporção observada no Brasil). Ao contrário dos relatos da epidemia em países desenvolvidos, a tuberculose apresenta-se em nossos

Cademos de Saúde Pública, RJ, 7 (2): 232-250, abr/jun, 1991 
dados com grande transcendência, provavelmente em consequeência da larga e crescente difusão do bacilo de Koch no MRJ. Outras infecções, também importantes, foram a candidiase (com episódios relatados em $64 \%$ dos casos), a pneumonia por P. carinii (29\%), a toxoplasmose (19\%) e as citamegaloviroses (10\%). A ocorrência de sarcoma de Kaposi foi mais elevada que a mencionada na literatura para mulheres adultas, ao redor de $1 \%$ (Saltzman et al., 1988).

\section{DISCUSSĀO E CONCLUSŌES}

A AIDS é, sem dúvida, um dos grandes problemas da Saúde Pública colocados, hoje, na cidade do Rio de Janeiro, concentrando $80 \%$ de todos os casos notificados no Estado. A relativa debilidade do sistema de vigilância epidemiológica, onde é freqüente a subnotificação, especialmente em relação aos casos assistidos pela rede privada de atençāo, bem como as dificuldades encontradas para a realização das investigaçōes epidemiológicas, são problemas que necessitam ser superados para possibilitar uma compreensão abrangente da questão.

Apesar destes obstáculos, os dados aqui apresentados permitem analisar a crescente participação que as mulheres adultas vêm demonstrando ao longo da epidemia de AIDS no MRJ. Em que pese o sub-registro presente bem como a não-realização das investigaçōes epidemiológicas para a totalidade das notificações existentes, ainda assim os dados disponfveis permitem-nos constatar a dinâmica acelerada desta síndrome nas mulheres.

As comparações realizadas com dados referentes a outros grupos populacionais semelhantes, realizados tanto para o conjunto do Brasil, como para o Canadá, revelam o caráter epidemiologicamente dinâmico assumido pela doença no MRJ com o grupo estudado.

Inicialmente apresentando um peso considerável em sua difusão, através da contaminação transfusional, observou-se que a epidemia de AIDS em mulheres cariocas vem revelando uma crescente participação das drogas injetáveis, bem como da transmissão sexual, a partir do aprimoramento no controle da qualidade dos bancos de sangue.

Chama também a atenção, o caráter diferenciado que a doença assume nas diferentes categorias de transmissão, de acordo com a faixa etária considerada. Ressalta-se, assim, o papel jogado pela transmissão sexual e pela utilização de drogas em mulheres jovens, o que certamente tende a repercutir no alastramento da epidemia, através de uma vertente não-abordada neste estudo, referente ao desenvolvimento da doença nos recém-nascidos (transmissão vertical). 
ANÅLISE

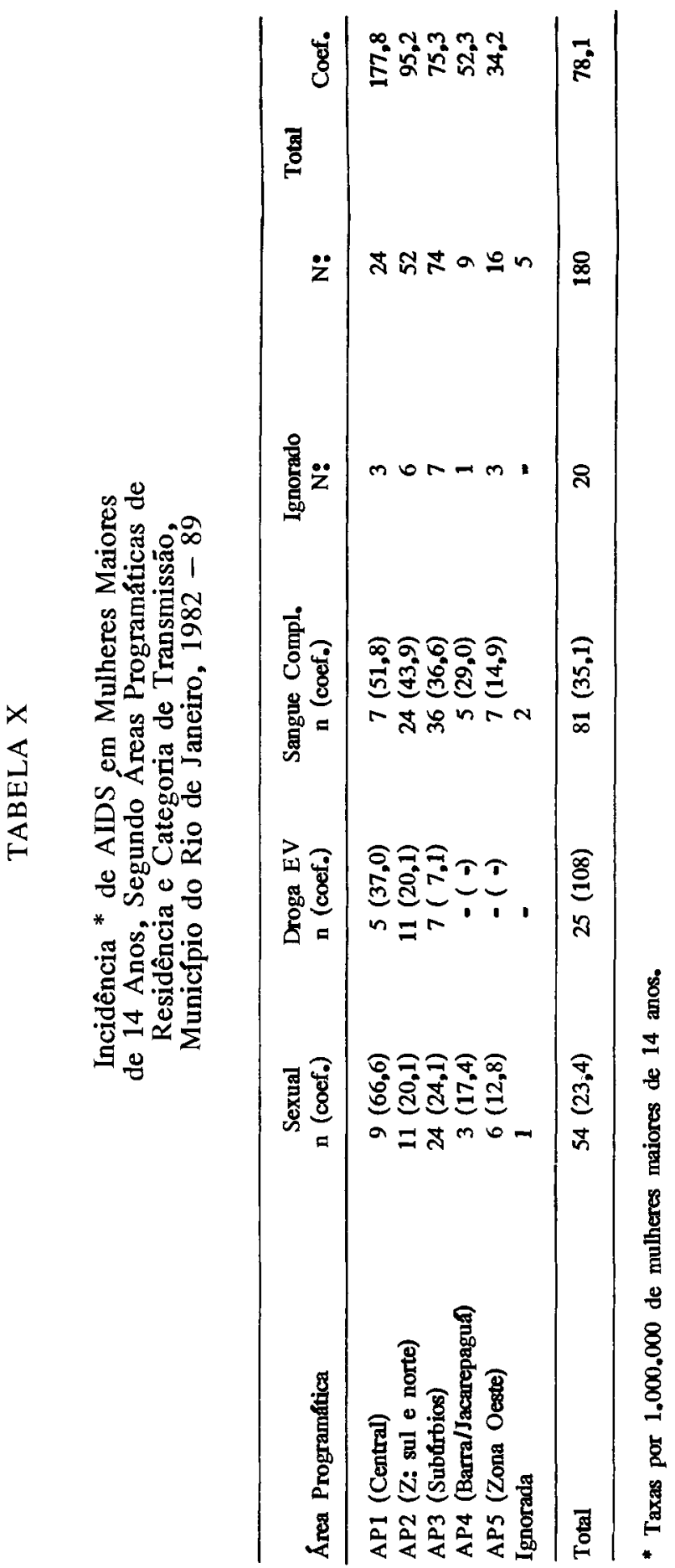


Distribuição de Patologias Associadas à AIDS em Mulheres Maiores de 14 Anos, Município do Rio de Janeiro, $1982-89$

\begin{tabular}{lrr}
\hline Patologia & Número & $\%$ \\
\hline Candidfase & 116 & 64,4 \\
Tuberculose & 52 & 28,9 \\
Pneumonia P. carinii & 41 & 22,8 \\
Toxoplasmose & 35 & 19,4 \\
Citomegalovirose & 18 & 10,0 \\
Herpes Simples & 12 & 6,7 \\
Criptococose & 8 & 4,4 \\
Outras Infeccöes Bacterianas & 8 & 4,4 \\
Isoponfase & 7 & 3,9 \\
Sarcoma de Kaposi & 6 & 3,3 \\
Encefalite & 6 & 3,3 \\
Herpes Zoster & 5 & 2,8 \\
Estrongiloidfase & 4 & 2,2 \\
Histoplasmose & 2 & 1,1 \\
Linfoma & 1 & 0,6 \\
\hline
\end{tabular}

- percentual referente a patologias observadas em 180 mulheres aidéticas.

Do ponto de vista de sua distribuição espacial, é notória a concentração observada através dos elevados coeficientes de incidência na área centro-sul do município, com indicadores de menor magnitude nas áreas de baixo nível sócio-econômico, como a região suburbana e zona oeste. Particularmente importante em termos da distribuição da doença no universo estudado foi a zona portuária (I RA), a qual apresentou taxas muito elevadas durante o periodo estudado.

Torna-se, assim, necessário aprofundar o estudo, envolvendo características e hábitos relativos à transmissão da doença nesta e noutras regiões, particularmente sobre os fatores de risco em subgrupos populacionais aí concentrados.

Para concluir, poderíamos afirmar que, entre os desafios futuros a serem enfrentados como forma de melhor compreender e, portanto, intervir na difusão da epidemia de AIDS, nẫo somente nas mulheres mas no conjunto da população, deveriam merecer destaque as seguintes questỗes: a magnitude da AIDS em mulheres adultas e a transmissão vertical; o redimensionamento da rede assistencial em termos da ampliação do número de leitos voltados para os casos de AIDS, dada a incidência crescente do problema; o aprofunda- 
mento na compreensão dos fatores envolvidos na dinâmica da transmissão da doença em mulheres de áreas localizadas, como aquelas da AP1 no MRJ; e a realizaçāo de estudos soroepidemiológicos sobre a presença do HIV nas mulheres em geral, bem como em subgrupos de risco (usuárias de drogas), prostitutas etc.).

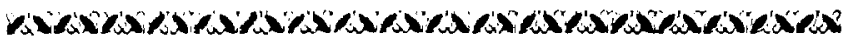

This paper presents the main epidemiological characteristics of AIDS cases observed among adult women in Rio de Janeiro Municipality (Rio) during 1980-89. Higher incidence rates as compared to Brazilian and Canadian women, rising participation of either sexual transmission and EV drug addiction and an increasing involvement of young women were also observed. The disease does not present a random spatial distribution in Rio, and case clusters in definite high risks areas were shown. Tuberculosis was found to be the second most frequent opportunistic infection detected among cases. Finally, some of the main trends and questions related to AIDS control among women in the studied area are discussed.

\section{REFERÊNCIAS BIBLIOGRÁFICAS}

BERKELMAN, R. L.; CURRAN, J. W. Epidemiology of HIV infection and AIDS, Epidemiologic Reviews, 11: 222-229, 1989.

CENTRE FOR DISEASES CONTROL. Revision of case definition of acquire immunodeficiency syndrome for natural reporting - United States. $M M W R, 34: 373-375,1985$.

CENTRE FOR DISEASES CONTROL. Diagnosis and management of mycobacterial infection and disease in persons with human T-lymphotropic virus type III/lumphadenopathy - associated virus infection. $M M W R, 35: 448-452,1986$.

CENTRE FOR DISEASES CONTROL. Human immunodeficiency virus infection in the United States: a review of current knowledge. $M M W R, 36: 1-21,1987$.

CENTRE FOR DISEASES CONTROL. Antibody to human immunodeficiency virus in female prostitutes. $M M W R, 36: 157-161$, 1987.

CHIN, J.; MANN, J. Global surveillance and forecasting of AIDS. WHO Bulletin, 67 (1): 1-7, 1989.

EUROPEAN STUDY GROUP. Risk factors for male to female transmission of HIV. Brit. Med. J., 298: 411-418, 1989.

FEDERAL CENTRE FOR AIDS. Surveillance Update: AIDS in Canada, Ottawa, Ontario, aug 7, 1990.

Cadernos de Så̊de Páblica, RJ, 7 (2): 232-250, abr/jun, 1991 
FIBGE. Centro Demográfico do Rio de Janeiro, IX Recenceamento Geral do Brasil. 1980.

FISCHL, M. et al. Seroprevalence and risks of HIV infection in spouses of persons infected by HIV. Abstract 4060. IV Intermational Conference on AIDS. Stockholm, 1988.

GOEDDERT, J. J, et al. Heterosexual transmission of human immunodeficiency virus (HIV): association with severe T4 cell depletion in male hemophiliacs. Abstract from the III International Conference on AIDS. Washington DC, 1987.

HOFF, R, et al. Seroprevalence of human immunodeficiency virus among childbearing women. N. Engl. J. Med., 318: 525-530, 1980.

JOHNSON, M. A.;WEBSTER, A. Human immunodeficiency virus infection in women. Brit. J. Obst. Gynaecol., 96: 129-134, 1989.

MANN, J. et al. The international epidemiology of AIDS. Scientific American, 256 (10): 82-89, 1988.

MINISTÉRIO DA SAÚ DE. AIDS. Boletim Epidemiolbgico, 1990.

$\mathrm{MOK}, \mathrm{J}$. G. et al. Infants born to mothers seropositive for human immunodeficiency virus. Preliminary findings from a multicenter European study. Lancet, 1: 1164-1168, 1987.

MORGAN, W. M.; CURRAN, J. W. Acquired immunodeficiency syndrome: current and future trends. Public Health Reports, 101: 459-465, 1980.

MOSS, A. R.; BACCHETTI, P. Natural history of HIV infection AIDS 3 (2): 55-61, 1989.

NZILAMBI, N. et al. Perinatal HIV transmission in two African hospitals, Abstract, II International Conference on AIDS, Washington DC, 1987.

SALTZMAN, B. R. et al. Comparison of AIDS clinical manifestations between men and women in primarily homosexual population. Abstract, IV International Conference on AIDS, Stockholm, 1988.

SEPRINI, E. E. et al, HIV infection and AIDS in newborn babies of mothers positive for HIV antibody. Br. Med. J., 294: $610,1987$.

ST ARCHER, E. T. et al. A trend analysis of the first 50000 AIDS cases reported in the United States. Abstracts, IV International Conference on AIDS, Stockholm, 1988.

WORLD HEALTH ORGANIZATION. World Health Statistics, Geneve, 1980. 